to subscribe to this doctrine. It is obvious that, for one who recovers, ninety-nine perish from the operation or from speedy return of the disease. The learning of the disasters to these ninety-nine probably affects the minds of several hundreds of friends and relations who hear about their unhappy fate. When a woman who knows all this discovers a lump in her breast, the unfortunate ends of persons whom she has known or heard about occur to her, and so frighten her that she conceals her complaint until she cannot do so any longer, and when she sees a surgeon it is too late for him to do any good. The operation is prejudiced in the eyes of the public, and for the one person in a hundred who escapes by some desperate operation, there are many who lose their lives by being terrified out of an early operation, which alone could have saved them. So I venture to recall once more the wise words of William Hunter, that the operation ought not to be undertaken without great probability of cure, as we run the risk of a general prejudice against the operation, which may so affright others that they will not run the hazard, though their disease may be really curable.

\section{NOTE AND REFERENCE.}

1 As illustrating William Hunter's quaint ways of speech, the following is his valedictory address at the end of the session : "Now, gentlemen, I have finished ye course and wish you all the success in ye world. It has given me a great deal of pleasure to attend to a number of gentlemen, who have made it their study from ye beginning to apply with assiduity to what was going on. Whatever you may think of it, I am always study. ing your good, and it is this alone which induces me to give lectures. have now finished twenty years of lectures, and however, as I presume am still approved of, I propose twenty years more to begin next October and, after this is over. I propose to settle in ye world and take me a wife." 2 Tumours of the Breast, 1880 .

\section{A (Clinital Perture}

ON

\section{OÖPHOREC'TOMY IN THE TREATMENT} oF

\section{CANCER OF THE BREAST.}

Delivered at St. Bartholomew's Hospital, Wednesday, November 20th. 1901.

By H. T. BUTLIN, D.C.L., F.R.C.S., Surgeon to St. Bartholomew's Hозрital.;

Gentlemen,-I have for some time past had it in my mind to lecture on the removal of the ovaries for malignant disease of the breast. I thought I would do so somewhat later in this year or in 1902, but one or two circumstances which have arisen lead me to lecture on it almost before I am prepared to do so. However, the only want in the preparation is that I shall not be able to tell you the story quite so concisely as I might have done if I had had a longer time to put it together. As to the facts and opinions they are not likely to be altered in another three months.

In the first place, some of you may remember a woman whom I showed in consultation some months ago, who was suffering from slight recurrence, not very severe, after amputation of the breast and removal of the glands. The recurrence was scattered, and was not convenient for local operation. She was about 40 years of age, still menstruating, and she had no apparent disease of bone or viscera. I brought her down to consultation, and placed before my colleagues the question of removal of the ovaries and tubes in accordance. with the treatment which has been employed from time to time for several years past. Various opinions were expressed, but nobody was hopeful of the success of the operation. Still, many of my colleagues thought it was a proper case on which to try the experiment, and. generally speaking, we agreed that the operation should be practised in that case. My colleague, Mr. Lockwood, removed the ovaries and tubes. I have just heard the end of that case, and I will tell it to you presently.

Then a lady came to me last week. I operated upon her and her sister within a few months of each other for cancer of the breast, and she came to ask me (not for herself, but for some other lady whom I have never seen, and who had been operated on by another surgeon), whether I thought it would be a good thing that her ovaries should be removed in order to prevent the recurrence of the disease, of which there is, as yet, no sign. I told her I was going to lecture on the question shortly. She wished to know whether the lecture would be published, and, if so, where, as she would like to read it, because she would like to know my opinion on the subject. Regarding her friend. I advised her for the moment not to have anvthing done. I tell you that because it shows that the matter has now become lay property, and people are beginning to talk of removal of the ovaries in certain cases of cancer of the breast.

At the time I showed my case at consultation I suppose everybody had in mind that the female organs of generation are related to each other, related, that is, in such a way that, for instance, when a woman is menstruating, a tumour of the breast, such as a cyst or a mammary glandular tumour, is said, and I daresay with truth, to get larger for the time being. And it is well known that during menstruation the breasts are apt to become painful and enlarged. So the relation between the ovaries and the breasts is a matter which is admitted by medical people, and is believed by women in all classes of society. But in May, i896, Dr. George Beatson, of Glasgow, who is attached to the Cancer Hospital there, read a paper before the Edinburgh Medico-Chirurgical Society on the Treatment of Inoperable Cases of Carcinoma of the Mamma: Suggestions for a New Method of Treatment: with Illustrative Cases. Dr. Beatson gave an account of two women to the Society, both of whom he showed. They had been treated by his new method, and eleven months after operation one of them appeared to be perfectly well of an absolutely inoperable condition of cancer.

Before I speak of the cases and of other cases in which the operation and thyroid treatment have been employed, I would like to draw your attention for a moment to his theory. The theory was not a mere general idea that the breast exercises a sort of influence on the generative organs, but he had certain definite views with regard to the nature of cancer of the breast which differed very considerably from those which hold the field at the present time. (I speak of the parasitic origin of cancer, which many people believe in, although it has not yet been proved.) Dr. Beatson considered that cancer of the breast is due to proliferation of the epithelium of the breast. It is a "local proliferation of epithelium," and he said when the cells had proliferated and increased in number, and could not escape from the acini or make their way from the ducts, they gradually swarmed out into the surrounding tissues, and produced the microscopic structure of cancer. He said there was no parasitic character about the disorder, and no special parasite had been seen, because there is no parasite in cancer of the breast. Taking this view of the nature of cancer, and believing it to be a mere proliferation and overflow, so to speak, of the epithelium of the breast, he began to consider what might control or alter this proliferation. I may tell you that this matter was before his mind for manv years before he performed his operation. He remembered that in ordinary lactation there is a similar proliferation of epithelium, and the epithelium, as soon as it is formed, instead of filling up the acini and then overflowing into the surrounding connective tissue, undergoes rapid fatty degeneration and is passed away as milk, and so no harm comes to the woman, and he remembered that at such times women do not menstruate. So he thought, if a woman has local proliferation of epithelium of the breast not during the period of lactation, and we suppress the action of the ovaries, it seems possible that we might induce a fatty degeneration in this proliferating and swarming epithelium which might spoil it, so that it would be no longer harmful to the individual. So he proposed to himself that he would, some time or other, if he could find a suitable case, take out the ovaries and tubes, so as to be quite sure that no ovarian tissue was left. That is, in effect, Dr. Beatson's theory ; and it is well, before you perform or talk about this operation, that you should know what was in his mind. I wondered, until I read his paper-which is a very good one indeed-what had first led him to perform the operation of oöphorectomy for cancer of the breast. I found it was the result of long study and of speculative thought, and not a mere matter of chance. He considered the matter for a number of sears, and worked up a good deal of information in 
connection with it before he thought of putting it into practice. This is what Dr. Beatson says :

We must look in the female to the ovaries as the seat of the exciting cause of carcinoma, certainly of the mamma, in all probability of the female generative organs generally, and possibly of the rest of the

So that he carried his idea of the influence of the ovaries on cancer over a much larger and wider area than the mere connection with cancer of the breast. In another place he says :

To recapitulate, I would urge the following points : (I) That there seems evidence of the ovaries and testicle having control in the human body over local proliferations of epithelium. (2) That the removal of the tubes and ovaries has an effect on the local proliferation of epithelium which occurs in carcinoma of the mamma, and helps on the tendency carcinoma naturally has to fatty degeneration.

You know that in carcinoma of the breast particularly a section of the carcinoma exhibits quantities of little yellowish points. Those are points of fatty degeneration.

(3) That this effect is best seen in cases of carcinoma in young people, a class of case where local removal of the disease is often unsatisfactory

I may say that this paper created a very considerable amount of interest in Edinburgh, and a discussion took place, in which a number of distinguished surgeons and pathologists took part. I do not know that Dr. Beatson's theories would have produced such an effect had it not been that he showed a woman, 33 years of age, who had been the subject of an operation for cancer of the breast, and in whom the disease had recurred to such an extent and in such a form that any further local operation was out of the question. He had then performed his operation of öophorectomy, and had treated her at the same time with thyroid extract. At the end of eleven months he was able to show her before the Medico-Chirurgical Society at Edinburgh, apparently quite cured of her disease. The nodules had softened, and become gradually smaller, and withered away, the woman completely regaining her health. You can imagine the pleasure he experienced at showing the success of his first operation, founded upon theories which were totally his own, and which never, so far as I have been able to discover, had been suggested by anybody else before that time. Dr. Beatson came to London in the course of 1897 , and delivered an address of very much the same kind at a meeting of the British Gynæcological Society. Again a discussion took place and various opinions were expressed, for the most part not very favourable to his method of treatment.

In the course of 1897 a discussion arose in the BrITIsH Medical Journal on what one might term objections on theory. Of course when a theory, a new practice dependent on that theory, is proposed for a serious disease like cancer of the breast, there are sure to be people who object, on theory alone. And the first objection of consequence was made by $\mathrm{Mr}$. Roger Williams, ${ }^{1}$ who at one time had been Registrar at the Middlesex Hospital, where there are cancer wards, and who had taken a great interest in cancer and had written a great deal about it, and a great deal which was very good. He pointed out that Sir Spencer Wells in his book on Ovarian Tumours had drawn attention to the occurrence of cancer after operations in which both ovaries had been removed. So far from those women being less liable to cancer than other women, they were found to be infinitely more liable to it, and the proportion of them who suffered from cancer of various parts of the body was extraordinary. But Mr. Roger Williams had not studied Dr. Beatson's paper carefully enough, because Dr. Beatson had already dealt with that point in his paper. Dr. Beatson replied, yes, that is perfectly true, but considering that in some of these women cancer occurred within a few weeks of removal of ovaries, and in many within a few months, in most of them within a year, it is only reasonable to believe that the ovaries which were removed were themselves the seat of some primary cancerous change. There were some who took one side in the discussion and others who took the other side. $\mathrm{Mr}$ Malcolm, ${ }^{2}$ of the Samaritan Hospital for Women, took the side of Dr. Beatson, and Mr. Whiteford ${ }^{3}$ took the side of Mr. Roger Williams. I do not know that much came of the continuance of the discussion, because nobody threw much fresh light upon it. But other real objections on theory were found in course of time. In the first place, it soon became apparent that the operation was not successful in all cases. More than that, in the majority of cases little or no effect was produced; and in a good many of those cases in which some effect, and sometimes a great effect, was pro duced the effect'was very transient. Then, again, it was very quickly discovered that the removal of the ovaries had no effect at all upon cancer of the uterus, ${ }^{4}$ and yet one would certainly have thought it ought to have quite as much as it would have on cancer of the breast. Again, Dr. Beatson suggested that the operation would be likely to be most useful in young people, that is to say, women under 30 or between 30 and 35 , but it soon became apparent that these were not the best subjects for the operation of oöphorectomy and the administration of thyroid extract. It was then suggested that it should be used for women of 40 to 50 years of age who were still menstruating and who had no visceral or bone disease, so far as could be ascertained. In 1897 there appeared a very good paper by Mr. Stanley Boyd, Surgeon to the Charing Cross Hospital, who has been the chief advocate for the treatment by oöphorectomy here in London. Mr. Stanley Boyd drew attention to a class of cases which had been mentioned in Dr. Beatson's paper, cases of women in whom carcinoma seems to stop and sometimes to get well. Let me give you an instance.

I operated upon a lady some years ago for an ulcerated cancer of the breast, around which were several small nodules. I pointed out to her medical man that the case was a very bad one so far as prognosis was concerned. In about a year I performed a second operation for nodules which were scattered beyond the scar, in the surrounding tissues. She made a very good recovery from each operation. Then these nodules recurred in greater number, and were more threatening than they had been before. I saw her two or three times, and she seemed to be getting weaker and weaker, and I felt that in a few months she would die. I met her family doctor about two years afterwards, and I said: "Oh, I am glad to see you ; I want to know when Miss W. died." He said, "She is not dead at all." I said, "Well, she must be in a very miserable condition." "No," he said, "she goes to the theatre and to dinner parties, and she is very well." I said, "What has become of those nodules?" He said, "Well" sometimes they are smaller, sometimes they seem larger, and sometimes they disappear. But, however that may be, she has no ulcerating places now, and she is in very good condition." Within three or four months from that time I was summoned to see the poor lady, and found her with the disease rapidly spreading. It had become suddenly active, and many of the nodules had ulcerated, and within a few weeks from that time she was dead. But the disease for a long time seemed to be arrested in her, and one had cause to hope that she might overeome it.

But the best case of this kind is one which was published by Mr. Pearce Gould, also of the Middlesex Hospital. He brought the patient before the Clinical Society of London several years ago. She was operated upon for cancer of the breast on several occasions; the disease recurred and affected many parts of the body, including almost certainly the right lung and the left femur. It seemed sure that she could not live long, when, without any particular reason and without any special treatment, she suddenly began to get a little better, and then gradually better and better, until at last every trace of cancer and every lump about her disappeared, and the woman appeared to have practically recovered from the diserse.

At the discussion on Mr. Gould's paper Mr. Bowlby mentioned a case of a similar kind which had been under the care of Mr. Willett, and the same disappearance of the disease had taken place. Now, Mr. Boyd might, of course, have used these cases against Dr. Beatson's practice, and he might have said: "Dr. Beatson, in his first case, happened. upon one of these instances in which a woman would have spontaneously recovered of the disease if she had been left alone, and if Dr. Beatson had not been rash enough to remove her ovaries and treat her with thyroid extract, she would have got well without anything being done." But, instead of taking that view, Mr. Stanley Boyd took a different, and I think a very sensible and interesting, view. He said it seems evident that in these two women some change of constitutinn took place, which rendered them no longer liable to the progress of the disease, and, more than that, which enabled them to withstand it, to thrust back, so to speak, the invasion, and finally to throw off the disease completely. 
And it seems to me, he said, very likely indeed that Dr. Beatson, by the removal of the ovaries, was able to produce in his patient a condition of constitution similar to that which naturally or unnaturally occurred in these two women under the care of Mr. Pearce Gould and Mr. Willett. At that time he had not performed the operation more than three or four times, and he mentioned that there was decided improvement in certain of the cases which had been under his care, and he thought it was worth while to go on with the operation.

I next come to my own experience. I have been so much consulted on questions of cancer for a good many years past that I believe I rank in this town as more or less of a cancer specialist, and naturally I am obliged to keep myself acquainted with every new suggestion for treatment, even tn the outward application of violets for the cure of internal cancer. I am asked about them incessantly. This very week a lady brings out a paper from her pocket and eays, "Have you seen this?" "Oh yes, I have seen it; vou mean the cure of cancer by violets, Lady Margaret Marsham ${ }^{6}$ who has been cured of cancer inside the throat by the application of violets outside?" That is what is called an authenticated case. However, I must confess that, for various reasons, perhaps chiefly the failure of many of the early cases, I did not follow, during the first two years, the treatment by oöphorectomy of cancer of the breast, as diligently as I ought to have done, until the matter was brought home to me forcibly, and perhaps not altogether pleasantly, by hearing that the operation had been performed on one of my own patients, and with perfect success. In 1890 I operated upon a woman in this hospital who came from the neighbourhood of Reading. I removed her breast and axillary glands by the old operation. In the course of a vear or two the disease came back, and she was sent up to the hospital here, and I showed her at the consultations. My colleagues and $I$ were agreed that the case was beyond the reach of further operation, and she went home, and I supposed she went home to die. But I received one day a letter to tell me that she had been operated upon by, I think, Dr. Walker, of Reading, who had removed her ovaries and tubes, with the result that this patient, whom I regarded as absolutely incurable, and had been supported by my colleagues in that belief, was cured of her cancer. I received a letter from the doctor or somebody else, asking me to see this woman, and saying she was going to be shown in London. I was sorry I was not able to see her, I think I was out of town for my holiday about that date. Presently I will tell you what further happened, but for the moment I am to consider it in the course of my story as a case cured by the operation of oöphorectomy, a case cured by somebody else, not with my ganction or even with my knowledge, but one of my cases which I had said could not be cured. Naturally then I began to take more interest in the matter. I had never performed the operation myself, but I spoke to people about it and put the matter before some of my patients, but few of them seemed inclined to undergn the operation. If I was asked about it in private. practice I said, "Yes, if you like to have it done, do so by all means, but I would rather you would get somebody else to do it."

There were various papers in 1898 by people who practiser the operation and without very great success, and in $1899^{7}$ again Mr. Stanley Boyd wrote in favour of it, and he read a very good paper at the meeting of the British Medical Association at Ipswich in $1900 .{ }^{*}$ In that he put tngether $4 \mathrm{I}$ cases in which the operation had been performed. He showed how much benefit some of these women appeared to have derived from this operation of oöphorectomy. I think Dr. Beatson himself at that time was not so hopeful of his own operation, and I believe it waslargely in consequence of Mr. Boyd's paper that my colleagues and I advised that woman in the winter to have the ovaries removed, and Mr. Lockwood performed the operation. We began to think it was a thing which we ought to try, but we wished to try it in the hospital, where microscopical examination could be made and full notes taken, and the case followed afterwards. This year the matter was again discussed at the meeting of the British Medical Association at Cheltenham, where Dr. Beatson read a paper upon it, ${ }^{9}$ and there is another paper by Dr. Herman. ${ }^{10}$ Both of these papers you will find in the JournaL in October. They are both worth looking at, but $I$ must confess $I$ am sur- prised at their hopeful tone. Dr. Beatson begins by giving an account of another case in which he performed the operation, and from the moment of the operation the patient began to improve, and rapidly got better. Her symptoms disappeared, and the lumps and tumours gradually went away. At the end of six months she was going on so well that he thought she would soon be quite cured. He says the doctor who was present spoke of it in a way which showed he was greatly impressed, and in one of his letters he made use of the expression." this seems like a romance." Then Dr. Beatson went on to say that, seeing the support he had received from various people, and how well they had spoken of itMr. Stanley Boyd, Dr. Herman, Mr. Eve, Mr. Watson Cheyne, and Mr. Lockwood had all spoken favourably of it-he felt justified in pushing the matter, and actually put before the meeting-he would not answer the question himself, but propounded it in the form of an inquiry-whether the time had not arrived when oöphorectomy and the administration of thyroid extract should be practised at the same time as amputation of the breast, or (and this is the important point) in the place of it. Well, the tone of his paper, and the questions which are being asked every now and again by people outside our profession, led me to look much more closely into the matter than I had ever done before. I met Mr. Lockwood, and said to him, "I see you have been speaking in favour of Dr. Beatson's treatment of cancer of the breast by oöphorectomy." He said, "No, I do not remember that, except in regard to the woluan at the consultation, and then I said that we ought to give it a trial." I said, "Have you done it often?" He said, "No, only in that case." I said, "I have a letter here frnm the doctor. He says, "Oöphorectomy gave no relief at all, though I think the growth was a little slower for the first month or so after the return from the hospital. Secondary nodules appeared," etc. In fact, she got worse and worse until she died. Then I looked to see what Mr. Eve had said upon it, and I found in 1899 that he had published an account of a case in which he had performed the operation. For five or six months the woman was better, but after that she became worse and died in about a year. ${ }^{11}$ Then I looked to see what Mr. Watson Cheyne had said. I found he had performed the operation on two young women, women, that is, aged between 30 and 35 , who were supposed to be the best subjects for the operation. Both those women appeared to have been improved for a short time, but then they became rapidly worse and died. He expressed his great disappointment at the result of the treatment; and said:

The result of these two cases, which were typical cases in young women ( 33 and 34 ) where the ovaries were still active, and where therefore their removal, if of advantage, should have produced the most marked results, is extremely discouraging, and I doubt if it is worth while going on with the procedure. ${ }^{2}$

At that very meeting of the Clinical Society Mr. Stiles, of Edinburgh. who was present at the reading of Mr. Beatson's first paper, mentioned that Dr. Beatson's first patient was growing rapidly worse. These are-his words :

Unfortunately in no instance had the patient been completely and permanently rid of the disease by removal of the ovaries. Only a few days back Dr. Beatson gave him (Mr. Stiles) an opportunity of again seeing his back Dr. Beatson gave him (Mr. Stiles) an opportunity of again seeing his first patient, in whom for several months all trace of the disease had disappeared. Recently, however, the disease had again become manifest, date. In the Edinburgh Royal Infirmary Dr. Beatson's treatment had been carried out by more than one surgeon, with the result that in some ceen carried out by more than one surgeon, with the result that in some cases the disease hiad

At the same time there appeared a short article or annotation in the BRItish MEdical Journal ${ }^{14}$ upon these results, saying :

Experience thus appears to prove that the operation influences cancer of the breasf favourably but not permanently. Even when improvement is long maintained, allowance must be made, as Mr. Marmaduke sheild has remarked. for the vagaries of recurrent cancer, the recent discussion at the Royal Medical and Chirurgical Society throwing much light on this important fact. We suspect, therefore, that oöphorectomy for the relief of inoperable cancer of the breast is a practice which will fall into disuse.

In the British Medical Jodrnal is a letter from Dr. Daniel McNicol to say that the patient mentioned in Dr. Beatson's last paper died on September 3 oth of this year. The last date given by Dr. Beatson was April 28th, only six months after the operation. From that moment she had ceased to improve, and "from that date till September 30 th, 
190I, her existence was simply a long drawn out, painful, and living death." 15

Of Dr. Herman's cases, I would only say that Case I appears at present to be one of the best on record. Of Case vir, of which he speaks as relieved by the operation, it is the opinion of those best fitted to judge of the result that, with the exception of having been relieved of dysmenorrhœa, she has not been in the least degree relieved so far as the malignant disease is concerned.

With regard to my own cured case, that is to say, the one which was operated upon at Reading. When three years ago Mr. Maxwell was following up all my cases he said:

I have come across a very curious case of a woman who died in the hospital at Reading. You removed her breast and the axillary glands and afterwards she had an operation performed on the abdomen. The question has arisen whether the operation on the abdomen was for malignant disease, and whether the primary disease in her case might not have been malignant disease of the ovary and not of the breast.

I said, "I can tell you about that case. It is a case which was cured by oöphorectomy." The house-surgeon had discovered the mark where the oöphorectomy was performed, but he had not known why the operation had been performed; he thought it was probably performed for tumour of the abdomen. The disease recurred just as it was before, but with much greater severity, and she died in February, 1898 . That patient, who had been reported to be cured, died of cancer just as if she had never been operated upon.

In looking up Mr. Stanley Boyd's last paper I noticed these things. He is not inclined himself to give the operation up at present. He finds that a beneficial effect is produced in a certain number of women, but he admits that most of the patients suffered from recurrence of the disease, or from recrudescence of it, if you like, within seven to twelve months after the oöphorectomy. He finds that the results are limited. Still, they are such as, in his opinion, justify the continuance of the experiment. I do not think he would go so far as to replace an ordinary amputation of the breast and removal of the glands by the operation of oöphorectomy. Now, of course it may be suggested to any of you, or it may occur to any of you, to say, "Well, after all, a great many of the local operations for cancer of the breast are not successful. The patient has a return of her cancerous disease, and dies of it. Under those circumstances we may as well practise one operation as another, and it may just as well be the operation of oöphorectomy as one of the large operations on the breast."

In order that the issues may be clearly placed before you I have thought them out, and I would like to point out to you the objects of the local operation for cancer of the breast. Take a woman who is euffering from a small cancer of the breast, with no affection of the glands, and there is a reasonable hope that, by a considerable operation, you may cure that patient in so far as she will not have cancer again. She is just as much cured as a patient who has had pneumonia. She may remain ten, fifteen, or twenty years without any cancer, and may die of some other disease. Again, take a woman who has cancer of the breast, with enlarged axillary glands. These you take away by a sufficient operation. The disease recurs in situ. That means failure of your operation up to a certain point. But, after all, she may be much less miserable, and may die a much less painful death than if the operation had never been performed. An example of that is the following:

Some years ago a lady was brought to me with a very bad cancer of the breast. She had very full breasts, and the whole breast was infiltrated with cancer. She had been under a quack for six or eight months before I saw her and her breast had become very hot, and hard and heavy. I pointed out that the prognosis was as bad as it could be. But on the other hand, as she suffered so much pain and was anxious to have something done, I amputated her breast. In the course of a few months the disease recurred in the form of numbers of nodules all about the breast region and in the other breast, which in the course of time became equally heavy and painful as the breast which had been removed. She absolutely begged me to remove the other breast on account of the pain she suffered in it; so that the operation was successful to that extent in her. I was much impressed by this. Again, several years ago, I was discussing removal of the breast of a lady with an old gentleman whose wife and sister-in-law had died, both of them from cancer of the breast. One of these ladies had been treated by operation and the other had not. One of the brothers was present, and be said, "What is the good of an operation if the cancer is to come back again as it did in my aunt?" The father said, "My dear boy, the difference in the death of those two women was enormous. The one who had no operation suffered grievously, whereas the patient on whom the operation was performed died a very much less miserable death."

Then, again, there are certain cases in which no recurrence takes place in situ. You remove the breasts and the axillary glands with perfect success so far that there is no local recurrence, and the disease occurs in some other part of the body. But there is no ulcerated mass, and the patient dies in much less misery. You may see such a case as this here every now and again. There is a little old woman who comes from one of the neighbouring workhouses, for whom I performed Halsted's operation four or five years ago. She has no. recurrence in sifu, but above the clavicle she has a large mass of glands which are not ulcerated. You may watch her gradually getting paler and thinner and feebler, and the perspiration breaks out upon her on the least exertion; but. she can be kept in perfect comfort by the injection of a dose of morphine from time to time.

So, too, I have of ten operated on women who, within a year or two, have died of cancer of the liver or another internal organ. In such cases the pain and distress are trivial compared with the pain and distress of an open cancer.

So we have really three objects in our operations for cancer of the breast:

First, the hope which we can hold out to a goodly number of women nowadays that operation may be quite successful.

Secondly, that if the disease still kills the patient, it may do so by occurring in some distant organ, and with much less pain and suffering.

Thirdly, that if it recurs in situ in the form of nodules, the patients generally suffer far liss than if no operation had been performed. We are asked to replace that by an operation for removal of the ovaries and the administration of thyroid extract. You are sure to be asked what the effect of this operation is. You can only reply that, so far as you know, there is no single case of cure, such cure as you get by local operation, by means of oöphorectomy. I do not know of a single case in which a patient can be claimed to have been cured by oöphorectomy,

Secondly, when the disease comes back again, as it generally does within six months to a year, and sometimes much more quickly, it does so exactly in the same form and with all the same trouble as were present at the time of the operation, and the patient grows slowly worse and dies. The manner of her death and the distress of it are not in the least changed by the operation of oöphorectomy.

Lastly, you have to admit that a very large number of women on whom oöphorectomy has been performed and who have been soaked in thyroid extract have not received the smallest benefit in the world. I am ready to admit that the operation of oöphorectomy, with the administration of thyroid extract, has for the most part been employed in very bad cases of cancer, very bad cases indeed, where the disease has recurred, and where there have been numbers of cancerous nodules scattered about the body. And the advocates of oöphorectomy may fairly say: "Let us have cases such as you operate upon with success by the local method."

I admit that if we are to come to a definite opinion as to whether this operation can cure any woman of cancer of the breast, it must be by applying the practice in, say, 20 or 25 cases of women who have cancer of the breast to a very limited extent and without any obvious extension to the lymphatic glands. If that number of patients can be found willing to take the risk I would not blame the surgeon who would perform oöphorectomy in such a series of cases but personally I have not the courage or the faith to do it myself.

REFERENCES

1 BRitish Medical Journal, 1897, i, 1514. 2 lbid., I897, ii, 185, 432, 1375 3 Ibid., 1897, ii, 117, 250.4 Ibid., 1897, ii, 89o. 5 Transactions, 1897, $\mathbf{x x x}, 205$ 6 Sunday Times, November 17 th. rgor. 7 BRITISH MEDICAL JoukNAL, 1899 1, 257. 8 Ibid., 19co, ii, 116r. 9 Ibid, 1901, ii, 1145. 10 Jbid., 1901, ii, 1150

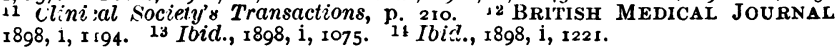

